\title{
Behavior of Ethidium Bromide-Hoechst 33258-DNA and Ethidium Bromide-Methylene Blue-DNA Triple Systems by means of UV Melting
}

\author{
Poghos O. Vardevanyan, Ara P. Antonyan, Marine A. Parsadanyan, \\ Mariam A. Shahinyan, and Gayane A. Melkonyan \\ Department of Biophysics, Faculty of Biology, Yerevan State University, A. Manoogian 1, 0025 Yerevan, Armenia \\ Correspondence should be addressed to Poghos O. Vardevanyan; biophys_dep@mail.ru
}

Received 23 September 2015; Revised 17 November 2015; Accepted 19 November 2015

Academic Editor: Hicham Fenniri

Copyright ( $) 2015$ Poghos O. Vardevanyan et al. This is an open access article distributed under the Creative Commons Attribution License, which permits unrestricted use, distribution, and reproduction in any medium, provided the original work is properly cited.

The study of EtBr and H33258 interaction as well as EtBr and MB interaction with DNA has been carried out. It was revealed that, at joint interaction, the effect of two ligands on the change of melting thermodynamic parameters of EtBr-DNA-H33258 or EtBrDNA-MB complexes is not an addition of separate interaction influences. It was shown that, at joint, binding of EtBr and $\mathrm{MB}$ with DNA competition occurs, while in the case of EtBr and H33258, the mutual strengthening of stabilizing effect of each of them on DNA double-stranded structure mainly takes place.

\section{Introduction}

Noncovalent binding of different compounds (ligands) with DNA is an object of numerous studies, since these substances possess high biological activity and influence on many vitally important processes occurring in the cells. Some ligands are mutagens (particularly, phenanthridine dye ethidium bromide $(\mathrm{EtBr})$ ) and transcription inhibitors (EtBr, actinomycin and other antibiotics) which is conditioned by the ability of these compounds to form slowly dissociating complexes and as a consequence of this DNA untwisting is obstructed [1-7].

According to the main interaction mechanism with DNA, ligands are divided into intercalators and groove binding compounds. $\mathrm{EtBr}$ and methylene blue (MB) represent a special interest as intercalators, Hoechst 33258 (H33258), as a groove binding ligand. $\mathrm{EtBr}$ is a strong mutagen as well as transcription inhibitor $[3,8,9] ; \mathrm{MB}$ is applied to the treatment of different diseases, including malaria and different types of tumors [10-16]. It was also revealed that MB may suppress viruses of AIDS and hepatitis B and hepatitis C in human blood plasma [10-16]. H33258 is a ligand specifically binding to AT sequences in DNA minor groove. Moreover, this ligand is also used in medicine, particularly, as an antihelminthic agent $[5,17-20]$.

Studies of DNA binding with these ligands showed many aspects of such interactions $[6-9,21]$. It was shown that many ligands bind to DNA mainly by several modes (multimodal ligands) $[8,11,20]$. Thus, for EtBr and actinomycin D, three modes of binding with double-stranded (ds-) DNA and two modes with single-stranded (ss-) DNA were revealed $[7,8]$. Nevertheless, there are few researches dedicated to the studies of simultaneous interaction of two different ligands with DNA, despite the fact that DNA is surrounded by numerous compounds and many of them may at the same time form complexes with it in the cells. There are theoretical studies where different models of formation of several types of complexes of the same ligand with DNA are discussed; moreover, these models cannot be referred to joint interaction of DNA with different ligands that bind by various mechanisms. From this point of view, those studies may be significantly relevant in which the joint interaction of two different ligands (either two intercalators and two groove binding ligands or one intercalator and one groove binding) with DNA is investigated for, nowadays, new 
multicomponent preparations having drug destination are synthesized.

The goal of the present work is to study the joint binding of two intercalators, $\mathrm{EtBr}$ and $\mathrm{MB}$, as well as $\mathrm{EtBr}$ and groove binding compound H33258 with DNA.

\section{Materials and Methods}

In the work, the following preparations were used: calf thymus DNA (“Sigma," USA), MB (“Aldrich," USA), H33258 ("Sigma," USA), and EtBr ("Serva," Germany). All preparations were used without additional purification in that they were ultrapure. Concentration of the used preparations was determined by absorption method applying the following molar absorption coefficients: $\varepsilon_{260}=6600 \mathrm{M}^{-1} \mathrm{~cm}^{-1}$ for calf thymus DNA [22], $\varepsilon_{664}=76000 \mathrm{M}^{-1} \mathrm{~cm}^{-1}$ for MB [16], $\varepsilon_{343}=$ $42000 \mathrm{M}^{-1} \mathrm{~cm}^{-1}$ for H33258 [23], and $\varepsilon_{480}=5600 \mathrm{M}^{-1} \mathrm{~cm}^{-1}$ for EtBr [24]. Experiments were carried out at $\mu=0.02 \mathrm{M}$ ionic strength of solution and $\mathrm{pH} \approx 7.0$. The concentration of DNA was equal to $7.6 \cdot 10^{-5} \mathrm{M}$.

The melting of DNA complexes with ligands as well as spectrophotometric measurements of absorption of preparation solutions was carried out on PYE Unicam-SP8-100 spectrophotometer (England). The heating of solutions of complexes was carried out by program device SP 876 Series 2 . For spectrophotometric measurements, quartz cuvettes with hermetically closed Teflon stoppers with $3 \mathrm{~mL}$ volume and $1 \mathrm{~cm}$ optic pathway length were used. Melting was carried out at $\lambda=260 \mathrm{~nm}$ wavelength corresponding to DNA maximal absorption. Absorption values of complexes at melting were displayed on PC monitor through a program elaborated in LabVIEW medium. The melting curves of complexes were constructed as described in [6].

DNA complexes with ligands were prepared according to $r=[C] /[P]$ concentration ratio, where $C$ is the concentration of one ligand (EtBr, H33258, or MB) or two ligands (EtBr$\mathrm{MB}$ or EtBr-H33258) and $P$ is the concentration of DNA phosphate groups. Values of $r$ were changed in $0<r \leq$ 0.33 interval. In the case of joint binding of two ligands with DNA concentration of each ligand was twice less to provide similarity of values of $r$ with those corresponding to DNA complexes with the mentioned ligands.

\section{Results and Discussion}

Among biologically active compounds interacting with DNA and significantly influencing its structural-functional characteristics EtBr takes a special place binding to DNA both in vivo and in vitro and inhibiting replication and transcription processes $[2-4,6]$. This ligand is a classical intercalator and an appropriate object for modelling of molecular mechanisms of interaction of different substances with DNA. The theoretical model of DNA helix-coil transition in complex with EtBr was elaborated which permits calculating heat value $(\Delta H)$ throughout dependence of temperature $\left(T_{m}\right)$ and melting interval width $(\Delta T)$ changes on ligand concentration, as well as carrying out thermodynamic analysis of DNA formed complexes with noncovalently binding ligands. Comparison of theory with experiment allows stating that $\mathrm{EtBr}$ forms three types of complexes with ds-DNA: intercalative, semiintercalative, and electrostatic [2-4, 6-9]. Moreover, these mechanisms of EtBr binding to DNA are universal. Particularly, it was shown that EtBr intercalation into DNA depends on ionic strength and $\mathrm{pH}$ of solution or other external factors $[8,25,26]$.

In the case of $\mathrm{MB}$, two (semi-intercalative and electrostatic) modes of binding to DNA at $0.02 \mathrm{M}$ ionic strength of solution and three (intercalative, semi-intercalative, and electrostatic) modes at $0.002 \mathrm{M}$ ionic strength have been revealed [25], which indicates that MB binding mechanisms with DNA are not universal (despite the fact that both ligands are intercalators). From this point of view, the binding peculiarities of these ligands with DNA at joint interaction are of special interest. In the case of $\mathrm{H} 33258$, two binding modes, strong and weak, were found out. Moreover, at relatively high ionic strengths of solution $(\mu>0.004 \mathrm{M})$, AT-specific (strong) and electrostatic modes of binding are shown, at $\mu \leq 0.004 \mathrm{M}$ : intercalative (strong) and electrostatic [5]. Therefore, in the case of MB and H33258, at least two binding modes with DNA are revealed, one of which is electrostatic. Displaying of this mode practically does not depend on solution ionic strength; the other mode is specific and its displaying depends on solution ionic strength.

These properties of the mentioned ligands may have practical value at both separate and joint interaction with DNA. For this aim, we have chosen two systems of multicomponent complexes, EtBr-DNA-H33258 and EtBr-DNA-MB, which were studied by the melting method and the changes of helix-coil transition parameters-dependencies of $\delta\left(1 / T_{m}\right)$ $\left(\delta\left(1 / T_{m}\right)=1 / T_{0}-1 / T_{m}\right.$, where $T_{0}$ and $T_{m}$ are melting temperatures of DNA and DNA-ligand complexes, resp.) and $\delta\left(\Delta T / T_{m}{ }^{2}\right)\left(\delta\left(\Delta T / T_{m}{ }^{2}\right)=\Delta T_{0} / T_{0}{ }^{2}-\Delta T / T_{m}{ }^{2}\right.$, where $\Delta T_{0}$ and $\Delta T$ are melting interval widths of DNA and DNA-ligand complexes, resp.) on $r$ were obtained [27].

Dependence curves of $\delta\left(1 / T_{m}\right)$ on $r$ of EtBr-DNAH33258 complexes (curve 1), additive curve obtained through summation of $\delta T_{m}$ values of DNA-EtBr and DNA-H33258 (curve 2), EtBr-DNA-MB (curve 3) complexes, and additive curve obtained through summation of values of $\delta\left(1 / T_{m}\right)$ for DNA-EtBr and DNA-MB (curve 4) complexes are presented in Figure 1. Values of $\delta\left(1 / T_{m}\right)$ and its dependence curves on $r$ in the case of DNA-EtBr, DNA-H33258, and DNA-MB complexes are presented in $[5,8,25]$. As it is obvious from Figure 1, curves 1 and 2, increasing in the whole interval of change of $r$, coincide with each other. Moreover, at joint interaction of EtBr and H33258 with DNA, values of $\delta T_{m}$ are higher (curve 1) depending on $r$, than in the case of summation of $\delta T_{m}$ values (curve 2).

This experimental result indicates that stabilizing effect of EtBr and H33258 on DNA double-stranded structure is not a simple sum of separate effects of these ligands. It is important that values of $\delta\left(1 / T_{m}\right)$ at joint binding of the mentioned ligands are higher than those of their separate binding. More interesting result is obtained for EtBr-DNA-MB complexes (Figure 1, curves 3 and 4). Comparison of curve 3 in Figure 1 with curves obtained for separate complexes of DNA-EtBr and DNA-MB shows that, at joint interaction of these 


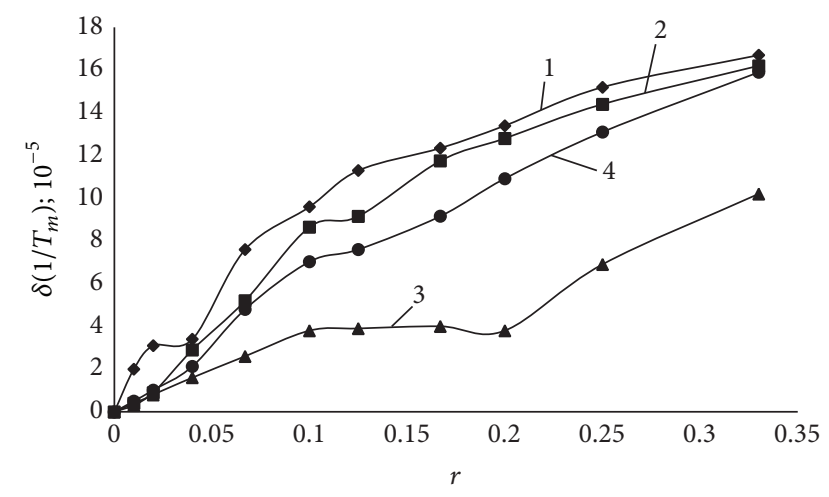

Figure 1: Curves of $\delta\left(1 / T_{m}\right)$ dependence on $r$ of EtBr-DNA-H33258 complexes (curve 1), additive curve obtained via summation of $\delta\left(1 / T_{m}\right)$ values of DNA-EtBr and DNA-H33258 (curve 2), EtBrDNA-MB (curve 3) complexes, and additive curve obtained via summation of $\delta\left(1 / T_{m}\right)$ values of DNA-EtBr and DNA-MB (curve 4) complexes. Concentration of DNA was equal to $7 \cdot 6 \cdot 10^{-5} \mathrm{M}$.

ligands with DNA, most probably, competition for binding sites emerges, in consequence of which an area on curve 3 (Figure 1) corresponding to change of $\delta\left(1 / T_{m}\right)$ in $0.1 \leq$ $r \leq 0.2$ interval appeared. In the mentioned interval of change of $r, \delta\left(1 / T_{m}\right)$ practically remains constant while at separate binding of $\mathrm{EtBr}$ and $\mathrm{MB}$ with DNA it increases in all interval of $r$ change. These results indicate that, at $0.02 \mathrm{M}$ ionic strength of solution at which $\mathrm{EtBr}$ and $\mathrm{MB}$ bind to DNA by intercalation mechanism, H33258-AT specifically, the competition is formed only between intercalators while $\mathrm{EtBr}$ and H33258 mutually strengthen the stabilizing effect of each other. Maintenance of this conclusion is that EtBr binding constant value $(K)$ with DNA by intercalation mechanism is higher by an order than value of $K$ at $\mathrm{MB}$ binding $[7,8]$. Moreover, value of $K$ at EtBr binding intercalation mode with DNA is lower by two orders than value of $K$ in the case of H33258 AT-specific binding to DNA $[5,8]$.

Dependence curves of $\delta\left(\Delta T / T_{m}{ }^{2}\right)$ on $r$ of EtBr-DNA$\mathrm{H} 33258$ complexes (curve 1), additive curve obtained through summation of $\delta \Delta T$ values of DNA-EtBr and DNA-H33258 (curve 2), EtBr-DNA-MB (curve 3) complexes, and additive curve obtained through summation of $\delta \Delta T$ values for DNAEtBr and DNA-MB (curve 4) complexes are presented in Figure 2.

Values of $\delta\left(\Delta T / T_{m}{ }^{2}\right)$ dependence on $r$ for DNA-EtBr, DNA-H33258, and DNA-MB complexes are presented in [5, $8,25]$. It is obvious from Figure 2 that $\Delta T$ change at joint binding of EtBr and $\mathrm{H} 33258$ with DNA is not sum alteration of this parameter (curves 1 and 2 in Figure 2). Moreover, at low concentrations of both parameters (in $0<r \leq 0.04$ ), EtBr effect on melting interval width of EtBr-DNA-H33258 complex prevailed, in $0.04<r \leq 0.1$ interval H33258 effect starts prevailing, and in $0.1<r \leq 0.33$ interval EtBr effect on $\Delta T$ strengthens. This fact is proved by data obtained via summation of corresponding dependencies of $\delta\left(\Delta T / T_{m}{ }^{2}\right)$ on $r$ (curves are not presented) for separate binding of the mentioned ligands with DNA, as a result of which curve 2 is formed which does not coincide with curve 1 (Figure 2).

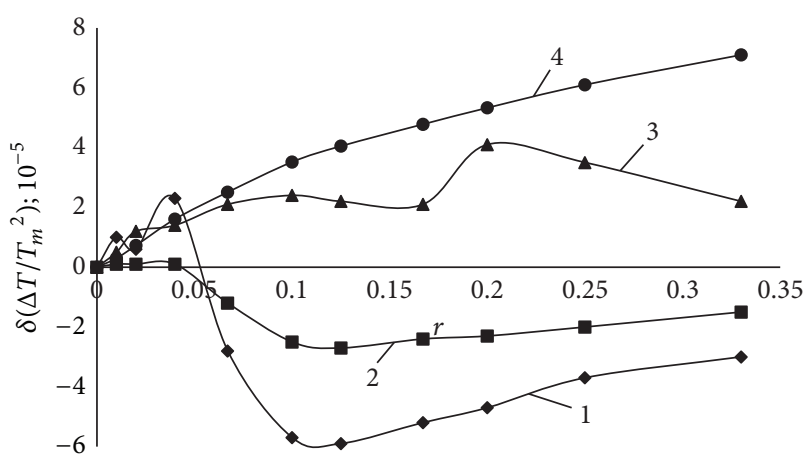

FIgure 2: Curves of $\delta\left(\Delta T / T_{m}{ }^{2}\right)$ dependence on $r$ of EtBr-DNA$\mathrm{H} 33258$ complexes (curve 1), additive curve obtained via summation of $\delta\left(\Delta T / T_{m}{ }^{2}\right)$ values of DNA-EtBr and DNA-H33258 (curve 2), EtBr-DNA-MB (curve 3) complexes, and additive curve obtained via summation of $\delta\left(\Delta T / T_{m}{ }^{2}\right)$ values of DNA-EtBr and DNA-MB (curve 4) complexes. Concentration of DNA was equal to $7 \cdot 6 \cdot 10^{-5} \mathrm{M}$.

As it is obvious from Figure 2, curve 3 which presents change of $\delta\left(\Delta T / T_{m}{ }^{2}\right)$ on $r$, at joint interaction of EtBr and $\mathrm{MB}$ with DNA, consists of two bell-like regions. It is the result of competition of $\mathrm{EtBr}$ and $\mathrm{MB}$ binding to DNA. Bell-like dependence of $\delta \Delta T$ on $r$ is inherent for $\mathrm{EtBr}$ [7] which is conditioned by several simultaneous binding modes of this ligand with DNA [6]. In the case of MB at $0.02 \mathrm{M}$ ionic strength of solution two binding modes are displayed $[25,28]$. Consequently, at enhancement of EtBr and $\mathrm{MB}$ concentrations, redistribution of $\mathrm{EtBr}$ and $\mathrm{MB}$ bound molecules (displacement of $\mathrm{MB}$ bound molecules by $\mathrm{EtBr}$ molecules) occurs during melting. Moreover, this effect is more pronounced at relatively high concentrations of both ligands when DNA molecules are mostly saturated by ligands. It is obvious from Figure 2 that additive curve 4 radically differs from curve 3 which proves the fact of the presence of competition at joint interaction of two intercalators with DNA.

\section{Conclusion}

Thus, the obtained data indicate that at joint interaction of two different ligands with DNA their effect on melting thermodynamic parameters of complexes is not the sum of separate effects of these ligands. Moreover, comparison of obtained data with theoretical ones, discussed in [29], indicates that joint interaction of two intercalators (EtBr and $\mathrm{MB})$ or intercalator $(\mathrm{EtBr})$ and nonintercalator (H33258) with DNA does not refer to one ligand interaction with DNA by two different modes. Furthermore, the obtained results reveal the competition at interaction of two different intercalators with DNA, which is not found out at interaction of one of them by several modes. It is ultimately interesting and important to highlight that at joint interaction of EtBr and $\mathrm{H} 33258$ with DNA mutual strengthening of stabilizing effect of each of them on double-stranded structure of DNA is revealed. These data may have practical significance at the screening of new preparations binding to DNA and influencing its various characteristics. These data are especially important because 
they may be applied in therapy of drug preparations since the majority of them at their separate effect with high doses have undesirable by-effects on cells. From this point of view, the joint application of different compounds having similar impact on various characteristics of DNA may give a positive effect in low doses (in the cases of both $\mathrm{EtBr}$ and H33258) or suppress the effect of one of them by the other (as in the case of $\mathrm{MB}$ and $\mathrm{EtBr})$.

\section{Conflict of Interests}

The authors declare that there is no conflict of interests regarding the publication of this paper.

\section{References}

[1] S. Neible and M. J. Waving, Molecular Aspects of Anti-Cancer Drug Action, Macmillan Publishers, London, UK, 1993.

[2] J. B. Chaires, "A thermodynamic signature for drug-DNA binding mode," Archives of biochemistry and biophysics, vol. 453, no. 1, pp. 26-31, 2006.

[3] A. N. Lane and T. C. Jenkins, "Thermodynamics of nucleic acids and their interactions with ligands," Quarterly Reviews of Biophysics, vol. 33, no. 3, pp. 255-306, 2000.

[4] R. R. Monaco, "A novel major groove binding site in B form DNA for ethidium cation," Journal of Biomolecular Structure and Dynamics, vol. 25, no. 2, pp. 119-125, 2007.

[5] P. O. Vardevanyan, A. P. Antonyan, M. A. Parsadanyan, K. V. Pirumyan, A. M. Muradyan, and A. T. Karapetian, "Influence of ionic strength on Hoechst 33258 binding with DNA," Journal of Biomolecular Structure and Dynamics, vol. 25, no. 6, pp. 641646, 2008.

[6] P. O. Vardevanyan, A. P. Antonyan, G. A. Manukyan, and A. T. Karapetyan, "Study of ethidium bromide interaction peculiarities with DNA," Experimental and Molecular Medicine, vol. 33, no. 4, pp. 205-208, 2001.

[7] R. M. Wadkins, E. A. Jares-Erijman, R. Klement, A. Rüdiger, and T. M. Jovin, "Actinomycin D binding to single-stranded DNA: sequence specificity and hemi-intercalation model from fluorescence and ${ }^{1} \mathrm{H}$ NMR spectroscopy," Journal of Molecular Biology, vol. 262, no. 1, pp. 53-68, 1996.

[8] P. O. Vardevanyan, A. P. Antonyan, M. A. Parsadanyan, H. G. Davtyan, and A. T. Karapetyan, "The binding of ethidium bromide with DNA: interaction with single- and doublestranded structures," Experimental and Molecular Medicine, vol. 35 , no. 6, pp. 527-533, 2003.

[9] A. N. Veselkov, S. F. Baranovkii, L. N. Dymant et al., "Complexformation of ethidium bromide with single-stranded noncomplementar deoxitetranucleotide $5^{\prime}$-d(ApApGpC)," Molecular Biology, vol. 31, no. 2, pp. 263-273, 1997.

[10] S. Nafisi, A. A. Saboury, N. Keramat, J.-F. Neault, and H.-A. Tajmir-Riahi, "Stability and structural features of DNA intercalation with ethidium bromide, acridine orange and methylene blue," Journal of Molecular Structure, vol. 827, no. 1-3, pp. 35-43, 2007.

[11] M. Hossain, P. Giri, and G. S. Kumar, "DNA intercalation by quinacrine and methylene blue: a comparative binding and thermodynamic characterization study," DNA and Cell Biology, vol. 27, no. 2, pp. 81-90, 2008.

[12] R. Hajian, N. Shams, and M. Mohagheghian, "Study on the interaction between doxorubicin and deoxyribonucleic acid with the use of methylene blue as a probe," Journal of the Brazilian Chemical Society, vol. 20, no. 8, pp. 1399-1405, 2009.

[13] C. Tong, Z. Hu, and J. Wu, "Interaction between methylene blue and calfthymus deoxyribonucleic acid by spectroscopic technologies," Journal of Fluorescence, vol. 20, no. 1, pp. 261-267, 2010.

[14] R. Rohs, H. Sklenar, R. Lavery, and B. Röder, "Methylene blue binding to DNA with alternating GC base sequence: a modeling study," Journal of the American Chemical Society, vol. 122, no. 12, pp. 2860-2866, 2000.

[15] R. Rohs and H. Sklenar, "Methylene blue binding to DNA with alternating AT base sequence: minor groove binding is favored over intercalation," Journal of Biomolecular Structure and Dynamics, vol. 21, no. 5, pp. 699-711, 2004.

[16] M. Hossain and G. S. Kumar, "DNA intercalation of methylene blue and quinacrine: new insights into base and sequence specificity from structural and thermodynamic studies with polynucleotides," Molecular BioSystems, vol. 5, no. 11, pp. 13111322, 2009.

[17] A. Abu-Daya, P. M. Brown, and K. R. Fox, "DNA sequence preferences of several AT-selective minor groove binding ligands," Nucleic Acids Research, vol. 23, no. 17, pp. 3385-3392, 1995.

[18] F. Han, N. Taulier, and T. V. Chalikian, "Association of the minor groove binding drug Hoechst 33258 with d(CGCGAATTCGCG) ${ }_{2}$ : volumetric, calorimetric, and spectroscopic characterizations," Biochemistry, vol. 44, no. 28, pp. 9785-9794, 2005.

[19] J. A. Parkinson, J. Barber, K. T. Douglas, J. Rosamond, and D. Sharples, "Minor-groove recognition of the self-complementary duplex d(CGCGAATTCGCG) 2 by Hoechst 33258: a highfield NMR study," Biochemistry, vol. 29, no. 44, pp. 10181-10190, 1990.

[20] K. Steinmetzer and K.-E. Reinert, "Multimode interaction of Hoechst 33258 with eukaryotic DNA; Quantitative analysis of the DNA conformational changes," Journal of Biomolecular Structure and Dynamics, vol. 15, no. 4, pp. 779-791, 1998.

[21] M. Hossain and G. S. Suresh Kumar, “Thermodynamic profiles of the DNA binding of benzophenanthridines sanguinarine and ethidium: a comparative study with sequence specific polynucleotides," Journal of Chemical Thermodynamics, vol. 42, no. 10, pp. 1273-1280, 2010.

[22] B. Norden and F. Tjerneld, "Structure of methylene blueDNA complexes studied by linear and circular dichroism spectroscopy," Biopolymers, vol. 21, no. 9, pp. 1713-1734, 1982.

[23] M. V. Mikhailov, A. S. Zasedatelev, and G. V. Durskii, "Mechanism of AT base pairs recognition by molecules of dye 'Hoechst 33258,' Molekuliarnaia Biologiia, vol. 15, no. 3, pp. 690-705, 1981.

[24] M. J. Waring, “The effects of antimicrobial agents on ribonucleic acid polymerase," Molecular Pharmacology, vol. 1, no. 1, pp. 1-13, 1965.

[25] P. O. Vardevanyan, A. P. Antonyan, L. A. Hambardzumyan, M. A. Shahinyan, and A. T. Karapetian, "Thermodynamic analysis of DNA complexes with methylene blue, ethidium bromide and Hoechst 33258," Biopolymers and Cell, vol. 29, no. 6, pp. 515-520, 2013.

[26] A. P. Antonyan, "Acidic denaturation of ethidium bromide complexes with DNA," Biological Journal of Armenia, vol. 65, no. 2, pp. 31-36, 2013.

[27] A. T. Karapetian, N. M. Mehrabian, G. A. Terzikian et al., "Theoretical treatment of melting of complexes of DNA with 
ligands having several types of binding sites on helical and single-stranded DNA," Journal of Biomolecular Structure and Dynamics, vol. 14, no. 2, pp. 275-283, 1996.

[28] P. O. Vardevanyan, A. P. Antonyan, M. A. Parsadanyan, M. A. Shahinyan, and L. A. Hambardzumyan, "Mechanisms for binding between methylene Blue and DNA," Journal of Applied Spectroscopy, vol. 80, no. 4, pp. 595-599, 2013.

[29] A. T. Karapetian, Z. A. Grigoryan, Y. S. Mamasakhlisov, M. V. Minasyants, and P. O. Vardevanyan, "Theoretical treatment of helix-coil transition of complexes DNA with two different ligands having different binding parameters," Journal of Biomolecular Structure and Dynamics, pp. 1-5, 2015. 

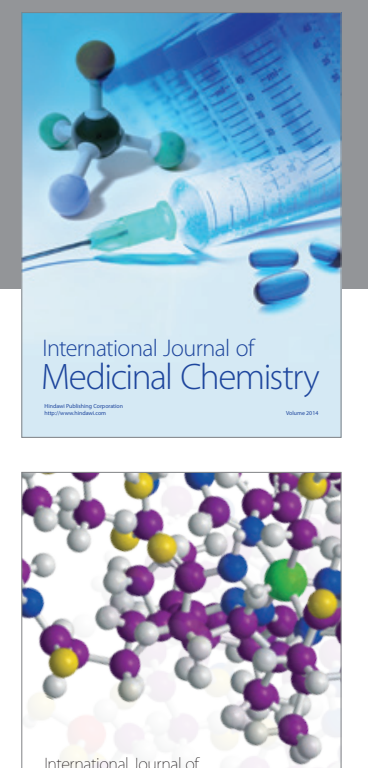

\section{Carbohydrate} Chemistry

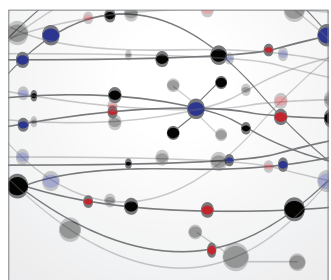

The Scientific World Journal
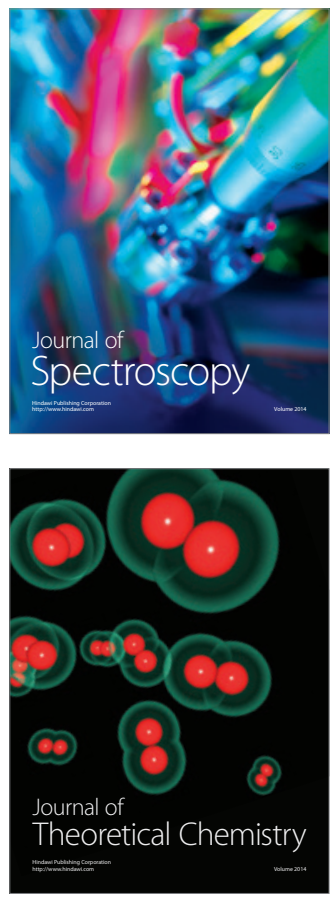
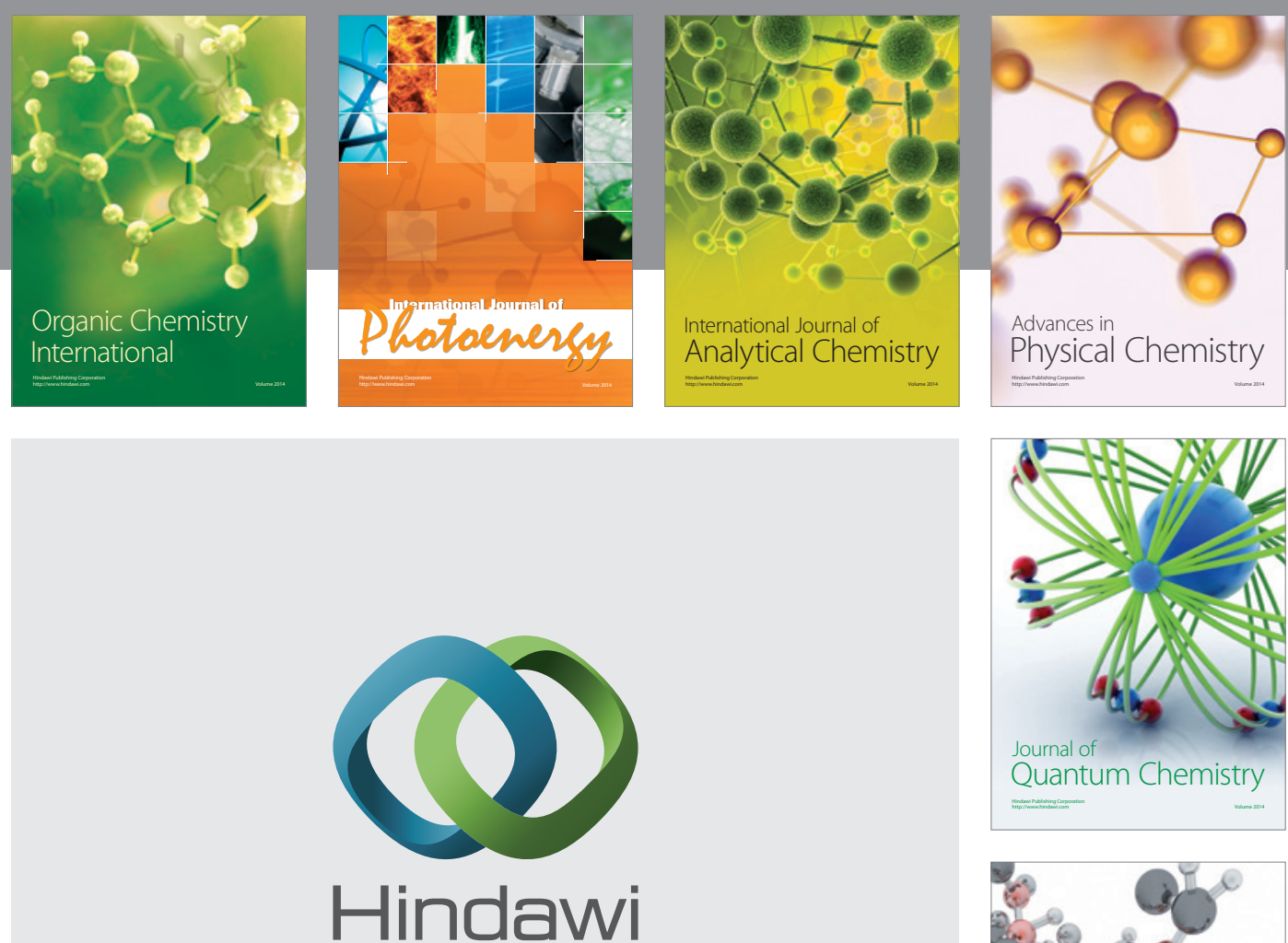

Submit your manuscripts at

http://www.hindawi.com

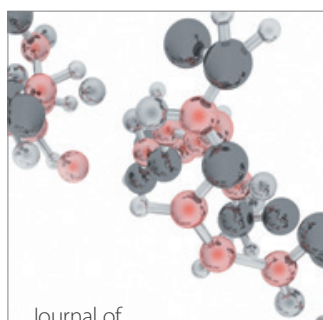

Analytical Methods

in Chemistry

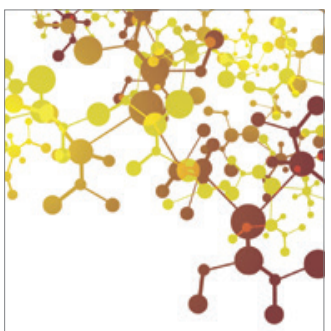

Journal of

Applied Chemistry

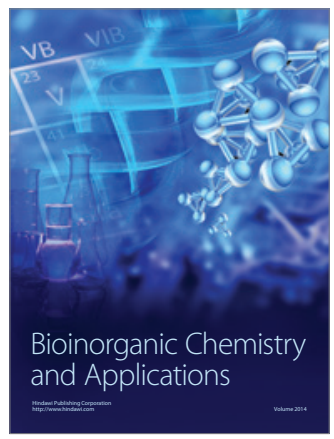

Inorganic Chemistry
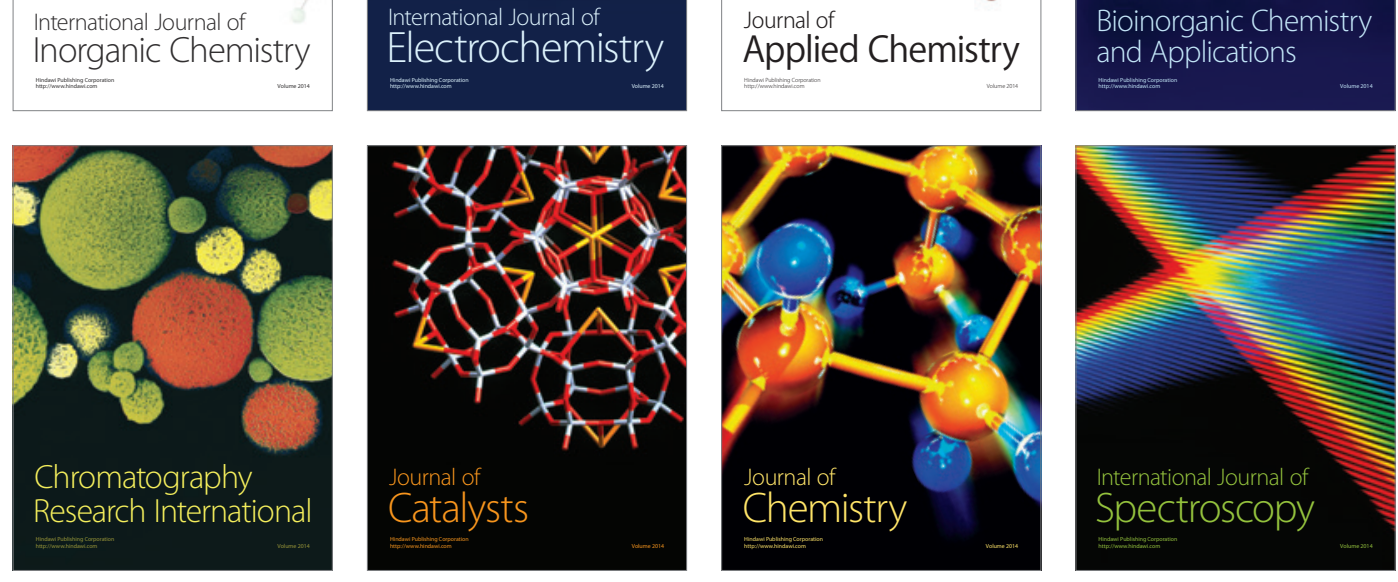